Acta Crystallographica Section D

\section{Biological Crystallography}

ISSN 1399-0047
Morten K. Grøftehauge, ${ }^{a *}$ Nelly R. Hajizadeh, ${ }^{a}$ Marcus J. Swann ${ }^{\mathrm{b}}$ and Ehmke Pohl ${ }^{\mathrm{C}}$ *

${ }^{a}$ Chemistry Department, Durham University, South Road, Durham DH1 3LE, England,

${ }^{\mathbf{b}}$ Farfield, Biolin Scientific, 62 Wellington Road South, Stockport, Cheshire SK1 3SU, England, and ${ }^{\mathbf{C}}$ Chemistry Department and School of Biological and Biomedical Sciences, Durham University, South Road, Durham DH1 3LE, England

Correspondence e-mail: m.k.groftehauge@durham.ac.uk, ehmke.pohl@durham.ac.uk

\title{
Protein-ligand interactions investigated by thermal shift assays (TSA) and dual polarization interferometry (DPI)
}

Over the last decades, a wide range of biophysical techniques investigating protein-ligand interactions have become indispensable tools to complement high-resolution crystal structure determinations. Current approaches in solution range from high-throughput-capable methods such as thermal shift assays (TSA) to highly accurate techniques including microscale thermophoresis (MST) and isothermal titration calorimetry (ITC) that can provide a full thermodynamic description of binding events. Surface-based methods such as surface plasmon resonance (SPR) and dual polarization interferometry (DPI) allow real-time measurements and can provide kinetic parameters as well as binding constants. DPI provides additional spatial information about the binding event. Here, an account is presented of new developments and recent applications of TSA and DPI connected to crystallography.

\section{Introduction}

The biophysical characterization of protein-ligand relations ranging from protein-ion and protein-drug interactions to protein-protein and protein-nucleic acid interactions plays a key role in structural biology. Methods routinely used to screen compound libraries span from highly specialized techniques requiring significant instrumentation and expertise such as NMR (Sillerud \& Larson, 2012) and mass spectrometry (Hofstadler \& Sannes-Lowery, 2006) to simpler methods including thermal shift assays (TSA) that determine a shift in melting temperature typically measured by changes in light scattering or by fluorescence techniques. Fluorescencebased techniques are often called Thermofluor assays or differential scanning fluorimetry (DSF; Pantoliano et al., 2001; Semisotnov et al., 1991; Vedadi et al., 2006). TSA can easily be performed in most laboratories and are now routinely used in drug discovery to identify new ligands in a high-throughput mode (Winter et al., 2012). In addition, TSA have been used by a number of groups to optimize crystallization conditions (Ericsson et al., 2006; Geders et al., 2012; Nettleship et al., 2008; Reinhard et al., 2013; Vedadi et al., 2006). A wide range of more sophisticated biophysical techniques can then be used to further characterize biomolecular interactions. Surface plasmon resonance (SPR) biosensor techniques available from various companies are used to determine kinetic parameters as well as the binding constants (typically in the range from subnanomolar to low millimolar) and stoichiometries of biomolecular interactions. SPR measurements are normally performed with intermediate throughput and hence are rarely applicable to chemical library screening. Applications and
Received 12 February 2014

Accepted 17 July 2014 
recent advances of SPR, including its important role in fragment-based drug-discovery projects, have been reviewed in a number of excellent recent articles (Homola, 2008; Patching, 2014; Rich \& Myszka, 2000). Isothermal titration calorimetry (ITC) is often considered to be the most accurate method to determine not only binding constants (in a typical range from subnanomolar to submillimolar) but also thermodynamic parameters (Freyer \& Lewis, 2008; Jelesarov \& Bosshard, 1999; Leavitt \& Freire, 2001). Being able to dissect the enthalpic and entropic contributions of biomolecular interactions also allows the study of dynamic changes in binding events (Rodgers et al., 2013; Tsvetkov et al., 2013; Tzeng \& Kalodimos, 2009). The high level of accuracy, however, requires the careful preparation of all buffers and milligram amounts of at least one of the components at $\mathrm{mg} \mathrm{ml}^{-1}$ concentrations. ITC measurements therefore represent a highly accurate but low-throughput method. More recently, microscale thermophoresis (MST) has emerged as a new and very promising method. MST is based on measuring the motion of molecules in a localized temperature gradient created by a highly focused infrared laser. This technique offers fast determination of binding constants using comparably small amounts of sample (Jerabek-Willemsen et al., 2011; Seidel et al., 2013). The method, however, requires specialized instrumentation at significant cost. Another relatively recent method to investigate biomolecular interactions is dual polarization interferometry (DPI), which is based on the physisorption of molecules onto the surface of a biochip. Binding events on the chip are tracked by monitoring specific interference patterns that are used to directly calculate the refractive index and the layer thickness (Cross et al., 2003).

In this article, we first present a short review of two techniques, TSA and DPI, that can be considered to be at opposite ends of the spectrum of biophysical methods. Applications and new developments will then be presented, including new

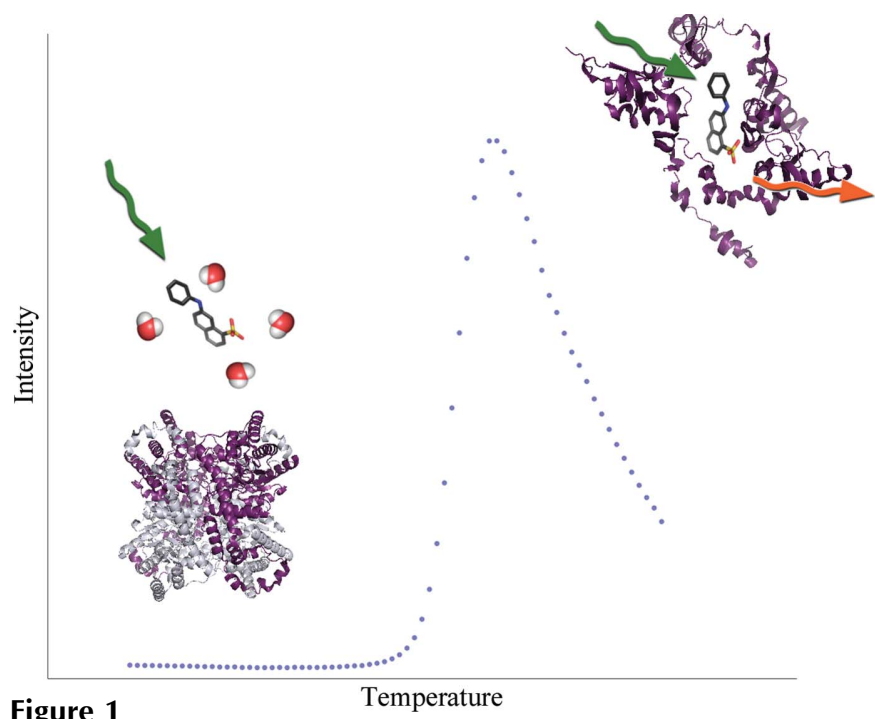

Figure 1

Temperature

Schematic representation of a thermal shift assay showing the melting curve (blue dots) of glucose isomerase (tetramer in ribbon representation) and a single 1-anilino-8-naphthalene-sulfonate (ANS) molecule (ball-and-stick representation). screens for crystallization that were designed to deconvolute the effects of individual ions, $\mathrm{pH}$ and types of buffers. In addition, analysis software programmed in Python is described that aids the analysis of TSA experiments. Finally, examples of dual polarization interferometry (DPI), which offers the potential to directly link thermodynamic parameters to spatial information, are shown.

\section{Methods review}

\subsection{Overview of thermal shift assays (TSA)}

The simplest and most commonly used method for TSA is the Thermofluor assay, in which a compound with a low fluorescence signal in a polar environment (such as in aqueous solution) but with high fluorescence in a nonpolar environment is added to a protein solution (Pantoliano et al., 2001). The fluorescence of the solution is monitored while the solution is heated. When the protein chain begins to unfold, the hydrophobic core becomes exposed and the signal increases until all protein molecules are completely denatured. Thus, the temperature of hydrophobic exposure at which half of the protein population is unfolded, $T_{\mathrm{h}}$, is determined (Fig. 1). A specialized variation of fluorescent TSA takes advantage of nonfluorescent compounds, such as CPM [7-diethylamino-3(4'-maleimidylphenyl)-4-methylcoumarin], that react specifically with the side chain of free cysteine residues to form fluorescent adducts, thus revealing the temperature at which buried cysteines become solvent-accessible. This technique requires excitation at approximately $384 \mathrm{~nm}$ and neutral $\mathrm{pH}$. Other thermal shift assays can be performed with highthroughput light scattering (Senisterra et al., 2006) or by determining the temperature at which the protein is no longer able to bind to high-affinity radiolabelled ligands (Tate, 2012). A Thermofluor assay with a SYPRO dye can be performed in standard quantitative PCR instruments (Lo et al., 2004). Although the assay works with most soluble protein samples under most conditions, some samples do not give a clear signal owing to denaturation to fibrils, high background caused by fluorophore binding to the protein in its native state or an insufficiently hydrophobic core. In general, increasing the thermal stability of a protein has many applications. Often, an additive that increases the thermal stability of a protein also decreases its dynamism and heterogeneity, making it more suitable for crystallography. In addition, a higher melting point of a protein also translates into a greater stability at lower temperatures, which can result in higher protein purification yields (Krintel et al., 2014) and an increased probability of crystallization. Here, we have used the Thermofluor assay with SYPRO Orange. The standard protein glucose isomerase is used here as a test system to demonstrate new standard screens and new analysis tools for TSA measurements.

\subsection{Overview of dual polarization interferometry (DPI)}

DPI shares many similarities with SPR since it is based on immobilizing one component on the surface of a biosensor. Binding events on the surface are then measured by tracking 
Table 1

Compositions of the $\mathrm{pH}$ screen.

Final concentrations of the screen when diluted $50 \%$ by addition of protein in buffer. Position A1 is used as the reference value. Buffers $A, B$ and $C$ are composite/ universal buffers (Newman, 2004) used at a concentration of $0.2 \mathrm{M}$. The composition of each buffer is given in $\S 2$.

\begin{tabular}{|c|c|c|c|c|c|c|c|c|}
\hline & 1 & & 2 & & 4 & 5 & 5 & 6 \\
\hline B & $0.1 M$ bis-tris propane $\mathrm{pH}$ & $\mathrm{H} 6.8$ & $0.1 M$ imidazole $\mathrm{pH} 6$ & 6.95 & $0.1 M$ MOPS pH 7.10 .1 & $.1 M$ phosphate $\mathrm{pH} 7.20 .1$ & $0.1 M$ HEPES $\mathrm{pH} 7.5$ & $0.1 M$ tricine $\mathrm{pH} 8.0$ \\
\hline $\mathrm{C}$ & Buffer $A \mathrm{pH} 4.0$ & & Buffer $A$ pH 4.4 & & Buffer $A$ pH 4.7 & Buffer $A$ pH 5.0 & Buffer $A$ pH 5.4 & Buffer $A$ pH 5.6 \\
\hline E & Buffer $C \mathrm{pH} 4.0$ & & Buffer $C$ pH 5.0 & & Buffer $C \mathrm{pH} 5.6$ & Buffer $C$ pH 5.8 & Buffer $C$ pH 6.3 & Buffer $C \mathrm{pH} 6.8$ \\
\hline $\mathrm{F}$ & $\mathrm{H}_{2} \mathrm{O}$ & & $\mathrm{H}_{2} \mathrm{O}$ & & $\mathrm{H}_{2} \mathrm{O}$ & $\mathrm{H}_{2} \mathrm{O}$ & $\mathrm{H}_{2} \mathrm{O}$ & $\mathrm{H}_{2} \mathrm{O}$ \\
\hline & $\begin{array}{l}\text { Buffer } B \text { pH } 5 \text {, } \\
\quad 0.8 \mathrm{M} \text { malonate }\end{array}$ & & $\begin{array}{l}\text { Buffer } B \text { pH } 7 \\
\quad 0.8 \mathrm{M} \text { malonate }\end{array}$ & & $\begin{array}{l}\text { Buffer } B \text { pH } 9 \\
\quad 0.8 M \text { malonate }\end{array}$ & $\begin{array}{l}\text { 3uffer } B \text { pH 5, } \\
0.4 M \text { malonate }\end{array}$ & $\begin{array}{l}\text { Buffer } B \mathrm{pH} 7 \\
0.4 M \text { malonate }\end{array}$ & $\begin{array}{l}\text { Buffer } B \text { pH } 9 \\
\quad 0.4 M \text { malonate }\end{array}$ \\
\hline & 7 & 8 & & 9 & & 10 & 11 & 12 \\
\hline A & $0.1 M$ citric acid $\mathrm{pH} 4.8$ & $0.1 M$ & id pH 5.6 & $0.1 \mu$ & $M$ MES & $0.1 M$ cit & $6.40 .1 \mathrm{M}$ ADA & $0.1 M$ bis-tris $\mathrm{pH} 6.75$ \\
\hline B & $0.1 M$ Tris- $\mathrm{HCl} \mathrm{pH} 8.1$ & $0.1 M$ & bicine $\mathrm{pH} 8.5$ & $0.1 \mathrm{~N}$ & $M$ bis-tris propane $\mathrm{pH} 9.0$ & $9.0 \quad 0.1 M$ CHES $\mathrm{pH} 9.5$ & $0.1 M \mathrm{CA}$ & $0.1 M$ phosphate $\mathrm{pH} 12$ \\
\hline $\mathrm{C}$ & Buffer $A$ pH 6.0 & Buffer & $\mathrm{r} A \mathrm{pH} 6.4$ & Buff & fer $A$ pH 6.9 & Buffer $A$ pH 7.6 & Buffer $A$ pH 9.2 & Buffer $A$ pH 10.0 \\
\hline & $\begin{array}{c}\text { Buffer } C \mathrm{pH} 5, \\
0.8 \mathrm{M} \mathrm{NaCl}\end{array}$ & $\begin{array}{c}\text { Buffer } \\
0.8\end{array}$ & $\begin{array}{l}C \mathrm{pH} \mathrm{7} \\
M \mathrm{NaCl}\end{array}$ & $\begin{array}{r}\text { Buff } \\
0.8\end{array}$ & $\begin{array}{l}\text { fer } C \mathrm{pH} \mathrm{9} \\
8 \mathrm{M} \mathrm{NaCl}\end{array}$ & $\begin{array}{r}\text { Buffer } C \mathrm{pH} \mathrm{5}, \\
0.4 M \mathrm{NaCl}\end{array}$ & $\begin{array}{c}\text { Buffer } C \mathrm{pH} \mathrm{7}, \\
0.4 \mathrm{M} \mathrm{NaCl}\end{array}$ & $\begin{array}{c}\text { Buffer } C \mathrm{pH} \mathrm{9,} \\
0.4 \mathrm{M} \mathrm{NaCl}\end{array}$ \\
\hline
\end{tabular}

Table 2

Compositions of the salt screen.

Final concentrations of the salt screen when diluted $50 \%$ by addition of protein in buffer. AS, ammonium sulfate; TMAO, trimethylamine $N$-oxide; TMG, trimethyl glycine.

\begin{tabular}{|c|c|c|c|c|c|c|}
\hline & 1 & 2 & 3 & 4 & 5 & 6 \\
\hline A & $\mathrm{H}_{2} \mathrm{O}$ & $\mathrm{H}_{2} \mathrm{O}$ & $\mathrm{H}_{2} \mathrm{O}$ & $5 \mathrm{~m} M$ SDS & $4.5 M$ urea & $0.5 M$ urea \\
\hline B & $1.5 \mathrm{M} \mathrm{NaCl}$ & $1.0 \mathrm{M} \mathrm{NaCl}$ & $0.8 \mathrm{M} \mathrm{NaCl}$ & $0.6 \mathrm{M} \mathrm{NaCl}$ & $0.4 M \mathrm{NaCl}$ & $0.2 \mathrm{M} \mathrm{NaCl}$ \\
\hline $\mathrm{C}$ & $1.5 \mathrm{M} \mathrm{Mal}$ & $1.0 \mathrm{M} \mathrm{Mal}$ & $0.8 \mathrm{M} \mathrm{Mal}$ & $0.6 \mathrm{M} \mathrm{Mal}$ & $0.4 M \mathrm{Mal}$ & $0.2 \mathrm{M} \mathrm{Mal}$ \\
\hline E & $0.5 M \mathrm{LiCl}$ & $0.2 M \mathrm{LiCl}$ & $0.5 M \mathrm{RbCl}$ & $0.2 M \mathrm{RbCl}$ & $0.5 \mathrm{M} \mathrm{CsCl}$ & $0.2 \mathrm{M} \mathrm{CsCl}$ \\
\hline $\mathrm{F}$ & $0.5 \mathrm{M}$ sodium formate & $0.2 \mathrm{M}$ sodium formate & $0.5 \mathrm{M}$ sodium malate & $0.2 \mathrm{M}$ sodium malate & $0.5 \mathrm{M} \mathrm{Na}_{2} \mathrm{NO}_{3}$ & $0.2 \mathrm{M} \mathrm{Na}_{2} \mathrm{NO}_{3}$ \\
\hline G & $0.4 M \mathrm{MgCl}_{2}$ & $5 \mathrm{~m} M \mathrm{MgCl}_{2}$ & $5 \mathrm{~m} M \mathrm{CaCl}_{2}$ & $5 \mathrm{~m} M \mathrm{SrCl}_{2}$ & $1 \mathrm{~m} M \mathrm{ZnCl}_{2}$ & $1 \mathrm{~m} M ~ N i C l_{2}$ \\
\hline $\mathrm{H}$ & $5 \mathrm{mM} \mathrm{Na}_{2} \mathrm{HPO}_{4}$ & $5 \mathrm{mM} \mathrm{Na} \mathrm{NO}_{4}$ & $5 \mathrm{mM} \mathrm{Na}_{2} \mathrm{WO}_{4}$ & 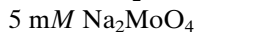 & $20 \%$ glycine & $10 \%$ glycine \\
\hline
\end{tabular}

\begin{tabular}{|c|c|c|c|c|c|c|}
\hline & 7 & 8 & 9 & 10 & 11 & 12 \\
\hline A & $1.5 \mathrm{M}$ AS & $1.0 \mathrm{M}$ AS & $0.8 M \mathrm{AS}$ & $0.6 \mathrm{M}$ AS & $0.4 M$ AS & $0.2 \mathrm{M}$ AS \\
\hline B & $1.5 M\left(\mathrm{NH}_{4}\right) \mathrm{Cl}$ & $1.0 M\left(\mathrm{NH}_{4}\right) \mathrm{Cl}$ & $0.8 M\left(\mathrm{NH}_{4}\right) \mathrm{Cl}$ & $0.6 M\left(\mathrm{NH}_{4}\right) \mathrm{Cl}$ & $0.4 M\left(\mathrm{NH}_{4}\right) \mathrm{Cl}$ & $0.2 M\left(\mathrm{NH}_{4}\right) \mathrm{Cl}$ \\
\hline $\mathrm{C}$ & $5 \mathrm{~m} M \mathrm{Gu}-\mathrm{HCl}$ & $1.0 \mathrm{M} \mathrm{Gu}-\mathrm{HCl}$ & $0.8 M \mathrm{Gu}-\mathrm{HCl}$ & $0.6 \mathrm{M} \mathrm{Gu}-\mathrm{HCl}$ & $0.4 M \mathrm{Gu}-\mathrm{HCl}$ & $0.2 M \mathrm{Gu}-\mathrm{HCl}$ \\
\hline $\mathrm{E}$ & $0.4 M \mathrm{NaF}$ & $0.1 M \mathrm{NaF}$ & $0.4 M \mathrm{NaBr}$ & $0.1 M \mathrm{NaBr}$ & $0.4 M \mathrm{NaI}$ & $0.1 M \mathrm{NaI}$ \\
\hline $\mathrm{F}$ & $0.5 \mathrm{M}$ sodium citrate & $0.2 \mathrm{M}$ sodium citrate & $0.5 \mathrm{M}$ sodium lactate & $0.2 \mathrm{M}$ sodium lactate & $0.5 \mathrm{M}$ sodium acetate & $0.2 \mathrm{M}$ sodium acetate \\
\hline $\mathrm{G}$ & $1 \mathrm{~m} M \mathrm{CoCl}_{2}$ & $1 \mathrm{~m} M \mathrm{CuSO}_{4}$ & $1 \mathrm{~m} M \mathrm{MgCl}_{2}, \mathrm{CaCl}_{2} \mathrm{ZnCl}_{2}$ & $5 \mathrm{~m} M \mathrm{MnCl}_{2}$ & $5 \mathrm{~m} M$ EDTA $\mathrm{pH} 8$ & $5 \mathrm{~m} M$ EGTA $\mathrm{pH} 8.9$ \\
\hline $\mathrm{H}$ & $1 M$ arginine $\mathrm{pH} 7$ & $1 M$ TMAO & $0.5 M$ TMAO & $0.5 M$ trehalose & $1 M \mathrm{TMG}$ & $0.5 M \mathrm{TMG}$ \\
\hline
\end{tabular}

the interference pattern from two waveguides: one with the biomolecules on the surface and a second buried reference waveguide. By alternating between two orthogonal polarizations, two independent measurements of the same surface are recorded and this enables the calculation of both the refractive index and the thickness of the layer on the biosensor. These raw data allow the determination of binding constants and in addition provide real-time information concerning conformational changes upon binding (Swann et al., 2004). Immobilization of a component can be achieved using different chips, ranging from unmodified surfaces to amine and thiol chips that allow binding by chemical bond formation, C18 chips optimized for binding by hydrophobic contacts and His-tags capture chips that are well suited to the His-tagged proteins frequently used in purification. Further details of the available chips can be found at http://www.farfield-group.com. DPI has been successfully used in applications ranging from biomolecular interactions to lipid structures (Hirst et al., 2011) and the study of protein crystallization (Boudjemline et al., 2011). Samples are first injected into a running buffer flow, 
which is passed over the waveguide sensor chip. First the sensor chip and running buffer refractive index are calibrated, followed by immobilization of the protein of interest onto the first of the two measurement channels, with the second channel acting as a control. Ligands can then be injected over the two surfaces. Immobilization can utilize a variety of methods from physisorption (Zwang et al., 2012) and chemical coupling (Karim et al., 2007) to specific binding (Coan et al., 2012). In the latter case, for example, a tag such as biotin can be employed to couple the protein to a streptavidin-coated sensor chip, in which case the second control channel would usually be just streptavidin-coated. The measurements provide information on the values of, and changes in, the thickness of the layer, the refractive index/density and the mass of the protein layer. It is important to note that these values will depend on the orientation of the protein on the surface. The protein will usually have a net orientation, even if just physisorbed, but the orientation can be controlled using a site-specific tag (Coan et al., 2012).

\section{Materials and methods}

\subsection{Thermal shift assays (TSA)}

3.1.1. TSA screens. All compounds for the two screens of 96 conditions each were purchased from Sigma-Aldrich or Fisher Scientific and were dissolved in Milli-Q water and filtered through $0.22 \mu \mathrm{m}$ filters. The $\mathrm{pH}$ screen was designed to deconvolute the effects of the $\mathrm{pH}$ and the buffer molecule on protein stability. The salt screen was designed to measure the effect of common salts and to deconvolute the respective effects of anionic and cationic species. The composition of the screens is given in Tables 1 and 2. The screens were designed with twice the concentration of the desired final concentration in the assay to allow assays to be set up using a 1:1 ratio of screen and protein plus dye solution. Universal buffers made with a mixture of buffer components that allow the effective control of $\mathrm{pH}$ over a wide range with the same buffer components (Newman, 2004) were prepared by making acidic stock solutions for each buffer with each of the three components at just above $200 \mathrm{~m} M$. Stocks were then adjusted to $\mathrm{pH} 4$ and $\mathrm{pH} 10$ with $\mathrm{NaOH}$, diluted to $200 \mathrm{mM}$ and mixed in 11:0, 10:1, 9:2, $\ldots, 0: 11$ ratios to create a $\mathrm{pH}$ range with each conjugate acid-base pair at $200 \mathrm{~m} M$ to give a total of $600 \mathrm{~m} M$. The $\mathrm{pH}$ was measured for each buffer at each ratio in $5^{\circ}$ increments from 25 to $80^{\circ} \mathrm{C}$ to determine the $\Delta \mathrm{p} K_{\text {a }}$ per degree. Buffer $A$ consisted of succinic acid, $\mathrm{NaH}_{2} \mathrm{PO}_{4}$ and glycine, buffer $B$ consisted of citric acid, HEPES and CHES, and buffer $C$ consisted of malonic acid, imidazole and boric acid (Newman, 2004). Equal ratios of buffer molecules were selected to simplify the deconvolution of the influence of individual species, despite resulting in a less equal spacing between $\mathrm{pH}$ values.

3.1.2. TSA measurements. Glucose isomerase from Streptomyces rubiginosus (purchased from Hampton Research; Carrell et al., 1989) was buffer-exchanged with 30-fold dilution in a spin concentrator (Sartorius Vivaspin 15, $30 \mathrm{kDa}$ mole- cular-weight cutoff), first three times into $20 \mathrm{~m} M$ HEPES$\mathrm{NaOH} \mathrm{pH} 7.5,5 \mathrm{~m} M$ EDTA-NaOH pH 7.5 and then two times into $20 \mathrm{~m} M$ HEPES-NaOH pH 7.5. The protein solution was then diluted to $1 \mathrm{mg} \mathrm{ml}^{-1}$ and aliquoted in four Eppendorf vials with $1 \mathrm{ml}$ in each. $4 \mu \mathrm{l} 5000 \times$ SYPRO Orange in DMSO was added to each vial and mixed by stirring with the pipette tip to give a concentration of $20 \mathrm{~m} M$ HEPES-NaOH pH 7.5, $20 \times$ SYPRO Orange, $0.4 \%$ DMSO. $2 \mu \mathrm{l} 2.5 \mathrm{M} \mathrm{MgCl}_{2}$ were added to two of the vials to give a concentration of $5 \mathrm{mM}$ $\mathrm{MgCl}_{2}$. Each were pipetted into a standard 96-well PCR plate (Starlabs Semi-Skirted FAST) with $10 \mu \mathrm{l}$ in each well. $10 \mu \mathrm{l}$ of salt and $\mathrm{pH}$ screens were pipetted into the 96-well plates with an Innovadyne Screenmaker $96+8$ to give final conditions of $20 \mu \mathrm{l}$ in each well. Both screens were repeated with $\mathrm{MgCl}_{2}$. Fluorescence data were collected on an Applied Biosystems

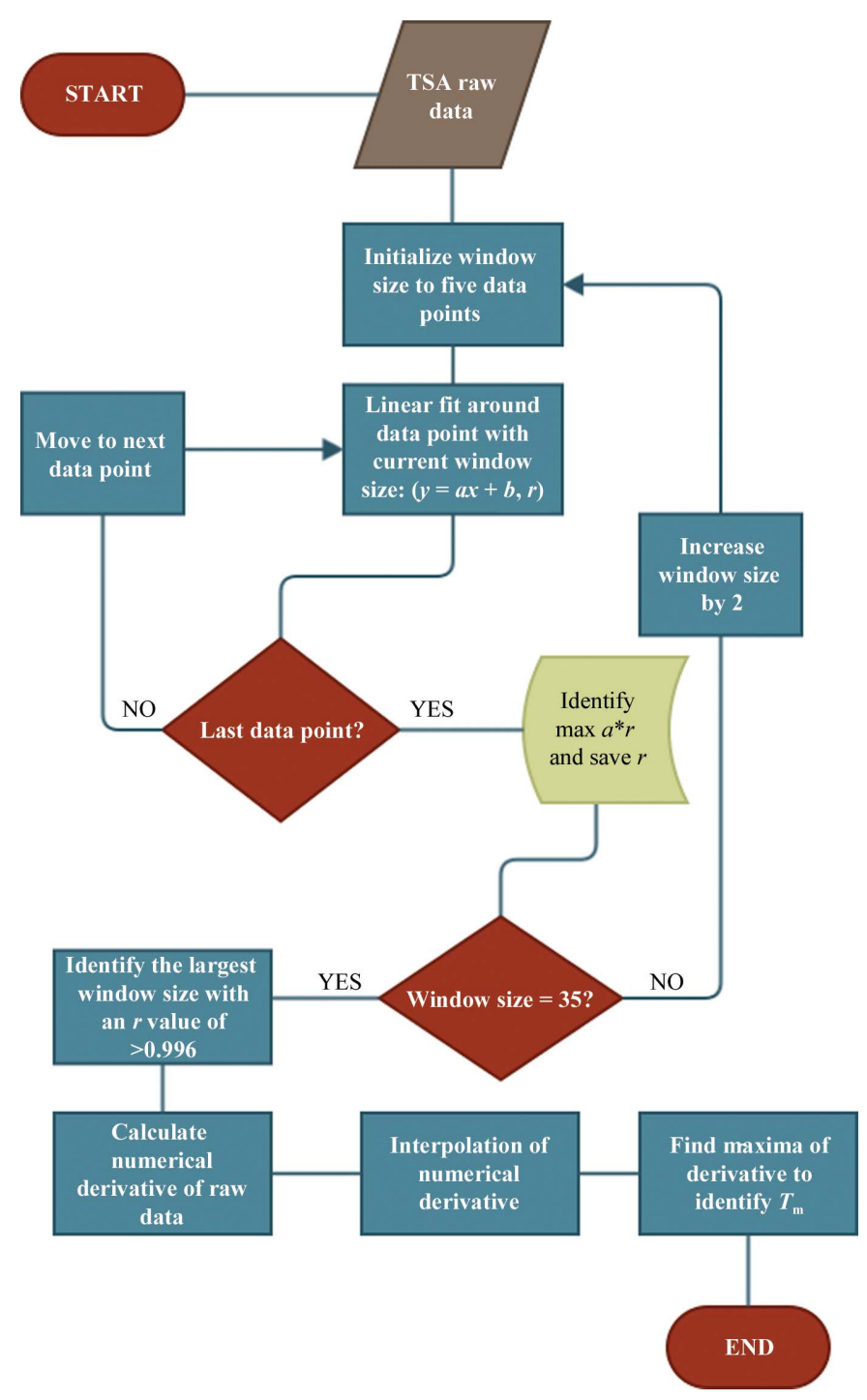

Figure 2

Flow diagram of $N A M I$, a program to analyse thermal shift assay data. Raw data are read in and analysed using a sliding window technique, where a window of increasing number of data points (5-35) is fitted by linear regression, resulting in a slope value $(a)$ and a correlation coefficient $(r)$ for each window. The optimal window size has been empirically found to be the one with the largest window size and $r>0.996$. 
7500 FAST RealTime PCR System with an excitation range of $510-530 \mathrm{~nm}$. The fluorescence emission signal at 567-596 nm was used for data analysis. The temperature was held for $1 \mathrm{~min}$ per degree from 24 to $95^{\circ} \mathrm{C}$.

3.1.3. TSA data analysis. In order to enable fast and automatic data analysis, a program, NAMI, was written in Python. Given the heterogeneity of the data, a purely analytical approach by differentiation of the raw data or a fitted function proved to be suboptimal. Therefore, a numerical approach was chosen to identify $T_{\mathrm{h}}$. The algorithm is summarized in the flowchart shown in Fig. 2. First, the fluorescence data and optionally the screen compositions are read as two commaseparated value (csv) text files. The denaturation window is then determined by applying a sliding window over the data set (fluorescence and temperature). The data in each window are fitted by linear regression, resulting in a slope value $(a)$ and a correlation coefficient $(r)$. This procedure is automatically repeated with increasing window range. The optimal window range has been empirically determined from test measurements from a wide range of proteins to have the steepest slope with a correlation coefficient of $r=0.996$. This window range is subsequently used to calculate the rate of change for each data point as an approximation for the derivative. In order to calculate a precise $T_{\mathrm{h}}$, the UnivariateSpline function from the SciPy package (Oliphant, 2007) is used to interpolate the experimentally derived data points. Up to two maxima are then reported as possible melting temperatures. Denaturation curves without a clear inflection point are automatically labelled N/S for no signal. The main GUI (shown in Fig. 3 with one representative melting curve) reads the composition of each experiment from simple text files (csv

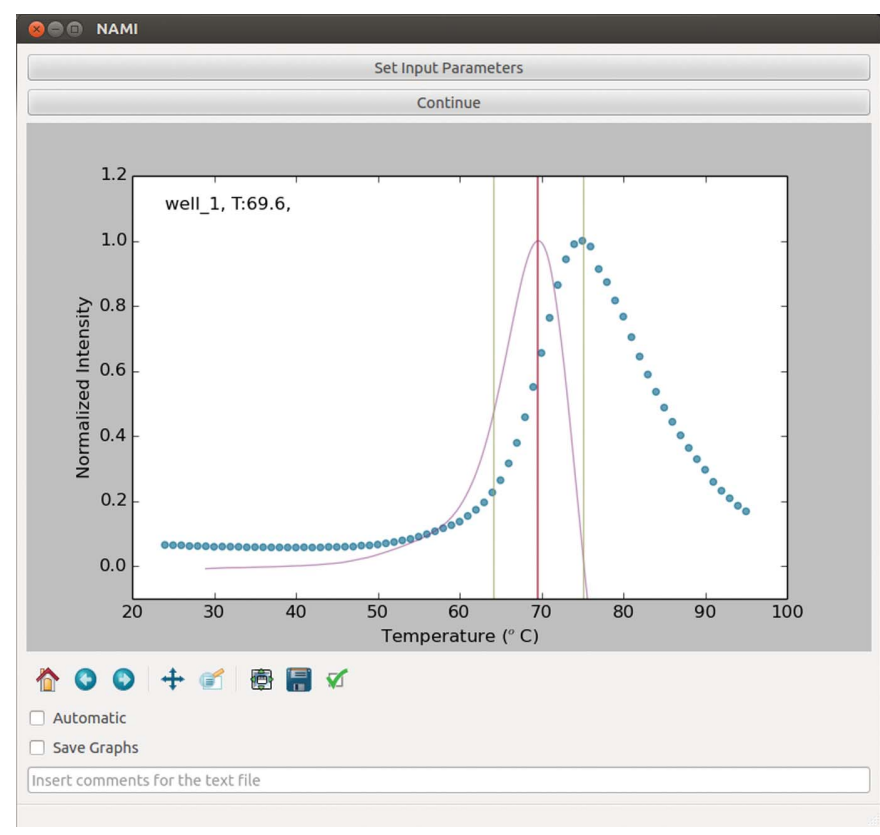

\section{Figure 3}

Main graphical user interface for TSA data analysis. The raw data are indicated as blue circles and the interpolated rate of change is shown in purple. The window used for determining $T_{\mathrm{h}}$ is shown as green vertical lines with $T_{\mathrm{h}}$ indicated as a red line. Options for automatic running and saving of all curves are indicated. format) and stores all results in new text files for manual inspection and/or subsequent analysis. These analysis tools will be explained in $\S 4$.

\subsection{Dual polarization interferometry}

3.2.1. $\mathrm{Cu}^{2+}$ binding to human serum albumin (HSA). Human serum albumin (HSA) is a high-molecular-weight endogenous plasma protein of $67 \mathrm{kDa}$. It is the main component of the blood transport system and reversibly binds a variety of endogenous (vitamins and lipids) and exogenous (drugs and toxins) molecules, distributing them to the target organs (Curry, 2009). HSA is also known to bind metal cations, which play crucial roles in human growth, development, cell division and synthesis of proteins and DNA. It is essential in the transport and metabolism of competitively bound $\mathrm{Cu}^{2+}$ ions in particular (Bal et al., 2013). Human serum albumin in $20 \mathrm{~m} M$ Tris, $500 \mathrm{~m} M \mathrm{NaCl}, 25 \mathrm{~m} M$ sodium sulfate $\mathrm{pH} 5.7$ was physisorbed onto an amine chip at a concentration of

\begin{tabular}{|c|c|c|c|c|c|c|c|c|c|c|c|c|}
\hline & 1 & 2 & 3 & 4 & 5 & 6 & 7 & 8 & 9 & 10 & 11 & 12 \\
\hline A & 67.3 & 64.4 & 65.1 & 60.7 & 58.5 & 63.7 & 60.1 & 68.1 & 68.5 & 67.3 & 67.7 & 66.9 \\
\hline B & 65.4 & 64.8 & 69.5 & 68.3 & 74.1 & 71.5 & 70.7 & 65.5 & 62.7 & 64.4 & 63.6 & 48.1 \\
\hline C & 50.0 & 59.8 & 64.7 & 67.2 & 68.4 & 68.2 & 68.0 & 68.2 & 67.7 & 67.9 & 67.7 & 66.7 \\
\hline D & N/S & 47.4 & 59.4 & 65.8 & 68.1 & 68.6 & 68.1 & 68.5 & 68.5 & 68.6 & 69.0 & 68.1 \\
\hline E & 56.4 & 63.6 & 65.5 & 66.4 & 66.5 & 66.2 & 66.0 & 65.6 & 67.3 & 65.5 & 65.4 & 64.5 \\
\hline F & 67.5 & 67.4 & 67.3 & 67.3 & 67.2 & 67.1 & 67.5 & 67.1 & 67.3 & 67.1 & 67.2 & 67.3 \\
\hline G & 67.9 & 68.4 & 70.5 & 61.6 & 68.1 & 69.7 & 68.1 & 68.7 & 69.8 & 67.1 & 67.2 & 68.8 \\
\hline H & 57.7 & 68.3 & 70.1 & 60.4 & 67.7 & 69.7 & 64.4 & 65.5 & 66.9 & 63.6 & 66.0 & 65.3 \\
\hline
\end{tabular}

(a)

\begin{tabular}{|c|c|c|c|c|c|c|c|c|c|c|c|c|}
\hline & 1 & 2 & 3 & 4 & 5 & 6 & 7 & 8 & 9 & 10 & 11 & 12 \\
\hline A & 83.5 & 82.1 & 82.7 & 77.0 & 57.6 & 63.1 & 58.6 & 71.9 & 70.8 & 66.7 & 67.9 & 79.1 \\
\hline B & 75.5 & 72.3 & 80.4 & 78.6 & 83.6 & 83.7 & 83.9 & 83.4 & 84.0 & 83.0 & 82.5 & 50.0 \\
\hline C & 48.2 & 58.0 & 64.2 & 66.9 & 68.8 & 72.4 & 74.4 & 75.7 & 77.9 & 78.5 & 78.4 & 75.2 \\
\hline D & \begin{tabular}{|l|}
38.0 \\
83.0 \\
\end{tabular} & 44.6 & 58.2 & 64.6 & 67.1 & 67.8 & 67.3 & 66.9 & $\mathrm{~N} / \mathrm{S}$ & 70.1 & 70.5 & 69.9 \\
\hline $\mathrm{E}$ & 54.0 & 62.6 & 65.0 & 65.7 & 65.9 & 66.4 & 68.5 & 71.9 & 76.2 & 78.7 & 78.0 & 75.5 \\
\hline F & 83.9 & 83.8 & 84.5 & 84.3 & 84.5 & 84.3 & 84.1 & 84.1 & 84.0 & 84.4 & 84.3 & 83.2 \\
\hline 4 & 66.8 & 66.9 & 71.1 & 61.0 & 67.8 & 70.2 & 67.0 & 66.9 & 70.7 & 66.0 & 67.5 & 70.5 \\
\hline H & 56.1 & 67.4 & \begin{tabular}{|l|}
$\mid 70.7$ \\
\end{tabular} & 59.2 & 67.0 & 72.1 & 63.7 & 67.8 & 73.5 & 62.9 & 67.8 & 74.2 \\
\hline
\end{tabular}

(b)

\section{Figure 4}

(a) Results of a Thermofluor assay with glucose isomerase using the $\mathrm{pH}$ screen, showing the melting temperature for each of the 96 wells. The colour-coding scheme indicates increases in melting temperature by a colour change from light blue to dark blue (largest increase) and decreases by colours from yellow to red (largest decrease). Green signifies either two stages in the melting process or heterogeneous data. (b) Results of a Thermofluor assay with glucose isomerase using the $\mathrm{pH}$ screen with $2.5 \mathrm{mM} \mathrm{MgCl} 2$ added. Note that in this screen row $\mathrm{F}$ was used as a control with only water. Position D1 ( $\mathrm{pH} 4)$ resulted in double peaks and was automatically marked as grey $=$ unreliable. Position D9 contained a foreign particle and hence gave an unreliable result. N/S stands for no signal which could be owing to a lack of sample or to denatured protein. 




Figure 5

Analysis of the $\mathrm{pH}$ screen based on the results in Fig. 4(b). The graph shows the melting temperature $T_{\mathrm{h}}$ as a function of $\mathrm{pH}$. The $\mathrm{pH}$ value is temperature-corrected by $\Delta \mathrm{p} K_{\mathrm{a}}$ per degree.

$4 \mathrm{mg} \mathrm{ml}^{-1}$. The running buffer was the same but contained only $150 \mathrm{~m} M \mathrm{NaCl}$. After immobilizing the protein on the surface, the chip was rinsed in running buffer, followed by a series of blank and $\mathrm{CuCl}_{2}$ injections at various concentrations.

\section{Results and discussions}

\subsection{Thermal shift assay of glucose isomerase}

After analysing the measurements of each individual well in the 96-well plate, all resulting curves can be displayed and stored (representatives for high-background, two-step denaturation and full denaturation are shown in the Supplementary Fig. S1). The melting temperatures of the TSA experiments with glucose isomerase are summarized in Fig. 4. The user can display the contents of individual wells by moving the cursor over each well position. The results of the first $\mathrm{pH}$ screen (no $\mathrm{Mg}^{2+}$ present) shown in Fig. 4(a) indicate two areas that increase the thermal stability, in particular positions B5-B7, corresponding to HEPES, Tricine and Tris buffer $\mathrm{pH}$ 7.5-8.1. In addition, positions G3, H3, G6, H6 and G9 corresponding to buffers at $\mathrm{pH} 9$ show a clear increase. The effect of $\mathrm{Mg}^{2+}$ was then evaluated by repeating the same screen under identical conditions except for the addition of $2.5 \mathrm{mM} \mathrm{MgCl}$ (Fig. $4 b$ ). It is apparent that the effects of buffer and $\mathrm{Mg}^{2+}$ are not simply additive: whereas $\mathrm{Mg}^{2+}$ in general increases thermal stability, most of the buffers in combination with $\mathrm{Mg}^{2+}$ have the opposite effect. A number of conditions are clearly detrimental to protein stability, such as C1, D2 and B12 (bis-tris pH 6.8, buffer $C$ pH 4.4 and phosphate buffer $\mathrm{pH} 12.4)$. The program offers a number of ways to further analyse the data using simple menu-driven choices, as exemplified in Fig. 5, in which the $\mathrm{pH}$ profiles of different buffers are summarized. It is evident that buffer $A$ (shown in grey) results in a higher thermal stability over a larger $\mathrm{pH}$ range compared with buffers $A$ and $B$.

The results for the general salt screen shown in Fig. 6 confirm that not only $\mathrm{Mg}^{2+}$, which is a known cofactor, but a number of other divalent transition metals including $\mathrm{Ca}^{2+}$ (position G3 and a known inhibitor of enzyme activity) as well as $\mathrm{Co}^{2+}$ (position G7) significantly increase the thermal stability. In this case $\mathrm{Na}^{+}$and $\mathrm{NH}_{4}^{+}$appear to have a stabilizing effect; however, these cations have a destabilizing effect when the same screen is repeated with $2.5 \mathrm{mM} \mathrm{MgCl} 2$ in the solution, which may suggest that they interfere with $\mathrm{Mg}^{2+}$ binding at high concentrations (data not shown). In order to further investigate the concentration dependency, an additional 96well screen was produced in which the concentration of a number of divalent transition metals was systematically halved by serial dilution starting from $10 \mathrm{~m} M$. The results for $\mathrm{Co}^{2+}$ and $\mathrm{Mg}^{2+}$ are summarized in Fig. 7, in which the full fluorescence data of each serial dilution series is shown first as waterfall plots. There is no stabilizing effect at the two lowest concentrations of $\mathrm{Co}^{2+}$ (approximately 5 and $10 \mu \mathrm{M}$ ); however, the binding-site concentration is approximately $15 \mu M$ (with a protein concentration of $120 \mu M$ and eight binding sites; Fig. $7 a$ ). At $20 \mu M$ the stabilizing effect of $\mathrm{Co}^{2+}$ is evident, with a significant shift in $T_{\mathrm{h}}$. In addition, the raw data reveal a shoulder at this concentration, which may be owing to partial occupancy of the metal-binding sites.

The stabilizing effect of both divalent metals is clearly visible in Figs. 7(b) and 7(c). However, it is also apparent that increasing the $\mathrm{Co}^{2+}$ concentration above the protein saturation decreases the thermal stability.

\subsection{Dual polarization interferometry}

The DPI experiment was performed to investigate the structural changes associated with the binding of $\mathrm{Cu}^{2+}$ ions to a physisorbed layer of human serum albumin (HSA). The protein was adsorbed onto the chip surface and initially formed a layer $4.2 \mathrm{~nm}$ thick, which indicates a flat orientation on the surface, as might be expected. This reduced slightly on rinsing to $3.98 \mathrm{~nm}$ thick, with a layer protein density of $0.6 \mathrm{~g} \mathrm{~cm}^{-3}$ and a mass per unit area of $2.38 \mathrm{ng} \mathrm{mm}^{-2}$ immediately before the first sample injection. The raw data for the copper-HSA interaction for the HSA-coated channel are shown in Fig. 8. After the blank injection and control channel

\begin{tabular}{|c|c|c|c|c|c|c|c|c|c|c|c|c|}
\hline & 1 & 2 & 3 & 4 & 5 & 6 & 7 & 8 & 9 & 10 & 11 & 12 \\
\hline A & 66.0 & 65.9 & 66.0 & 64.0 & 51.8 & 63.2 & 69.0 & 68.6 & 67.9 & 67.0 & 66.8 & 66.4 \\
\hline B & 66.7 & 71.3 & 73.4 & 66.4 & 67.2 & 66.5 & 62.2 & 63.1 & 64.1 & 76.2 & 65.7 & 65.8 \\
\hline C & 72.1 & 72.6 & 71.3 & 70.4 & 69.7 & 68.0 & 63.7 & 27.0 & 27.0 & 32.0 & 41.5 & 51.4 \\
\hline D & 84.7 & 84.7 & 84.7 & 84.7 & 84.7 & 70.5 & 69.3 & 68.8 & 68.2 & 69.3 & 67.3 & 68.0 \\
\hline E & 70.8 & 82.5 & 67.5 & 68.2 & 61.9 & 65.8 & 67.3 & 67.5 & 73.3 & 69.1 & 56.3 & 67.3 \\
\hline F & 67.8 & 68.4 & 68.1 & 66.2 & 70.4 & 67.5 & 69.1 & 65.6 & 66.0 & 66.0 & 67.7 & 67.7 \\
\hline G & 76.4 & 84.1 & 82.7 & 76.6 & 76.1 & 86.7 & 87.6 & 56.6 & 66.9 & 89.7 & 67.0 & 65.4 \\
\hline H & 65.9 & 67.5 & 67.5 & 67.5 & 67.4 & 67.7 & 58.1 & 66.8 & 66.4 & 67.2 & 68.2 & 67.0 \\
\hline
\end{tabular}

Figure 6

Melting temperatures $T_{\mathrm{h}}$ for each of the 96 wells of the salt screen obtained with glucose isomerase stripped of $\mathrm{Mg}^{2+}$. Increases in $T_{\mathrm{h}}$ with respect to the three blanks (A1-A3) are indicated in colours from light to dark blue (largest increase) and decreases in yellow to red (maximum decrease). 
have been subtracted from the data, the layer thickness, refractive index (RI), protein density (calculated from the changes in refractive index) and mass can be calculated (Cross et al., 2003). The real-time layer-thickness changes for the raw data are shown in Fig. 9.

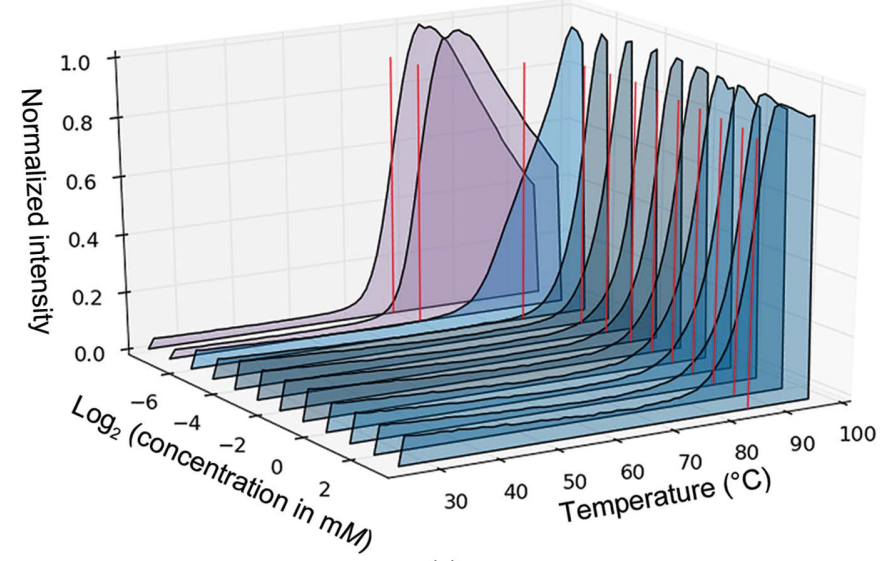

(a)

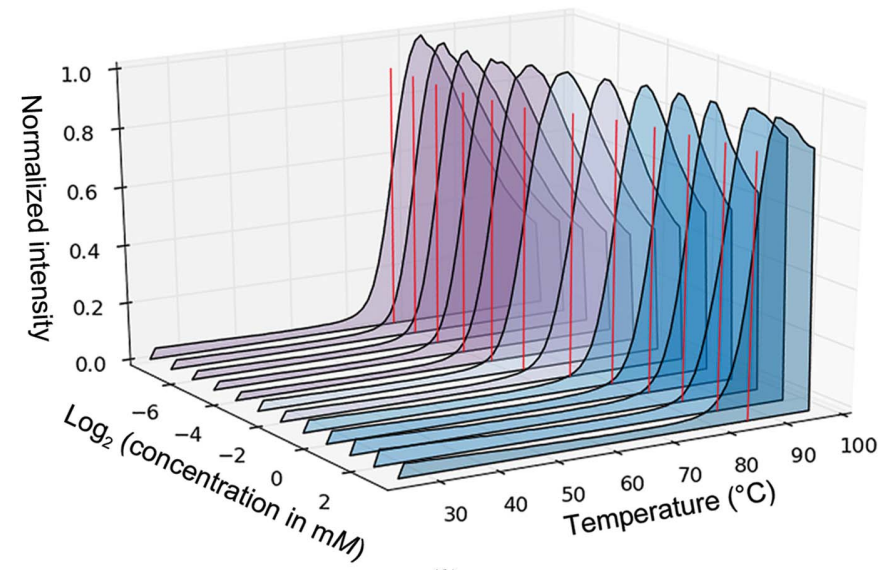

(b)

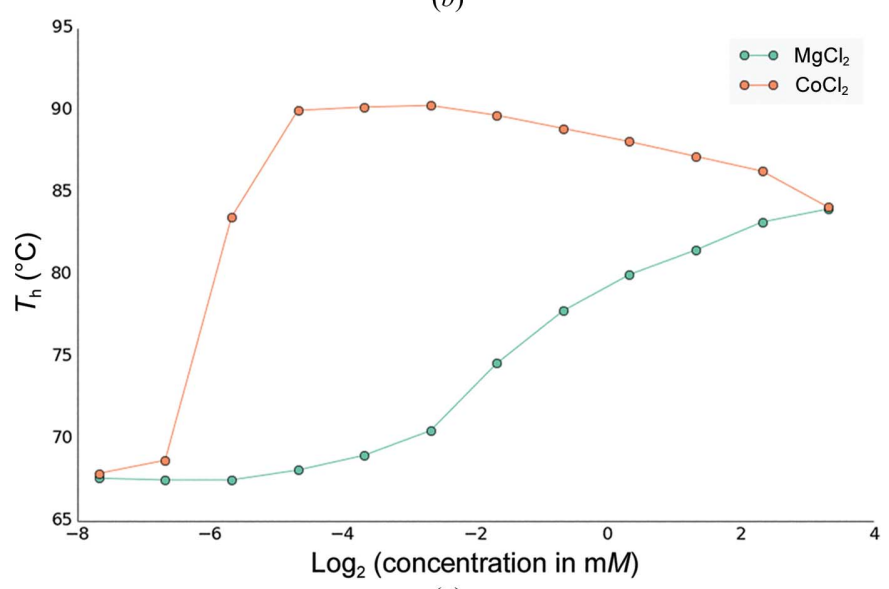

(c)

Figure 7

Examples of the analysis part of NAMI. (a) Waterfall plot of a follow-up screen in which the effect of the serial dilution of divalent metals on glucose isomerase is shown. The starting concentration of $\mathrm{CoCl}_{2}$ is $10 \mathrm{~m} M$. Purple curves indicate no significant difference from the reference; blue curves indicate a significant shift towards higher $T_{\mathrm{h}}$. (b) Waterfall plot of increasing $\mathrm{MgCl}_{2}$ concentration starting at $10 \mathrm{mM}$. (c) Melting temperature $T_{\mathrm{h}}$ as a function of the concentration of $\mathrm{CoCl}_{2}$ and $\mathrm{MgCl}_{2}$, respectively.
Binding of the $\mathrm{Cu}^{2+}$ ions can be seen to compress the HSA structure in a rapid and reversible process, causing a reduction in the layer thickness and a concomitant increase in the layer density (grams per millitre of protein within the HSA layer). HSA binds copper at several different sites, where multiple binding mechanisms cause very different structural changes. This effect can be seen as marked differences in the time or concentration dependence of these plots (Thibault et al., 2006). Similarly, different ligand interactions can also be differentiated by different conformational changes (Coan et al., 2012). In this case, thickness and density do not show marked differences; however, a plot of equilibrium thickness versus density as a function of copper ion concentration shows a change of slope at $\sim 10 \mu M$ (data not shown), which would indicate that the higher affinity site produces a stronger conformational change.

Affinity constants can be derived from the saturated equilibrium values usually from the phase or mass (Fig. 10). Here, a single-site affinity model is calculated at $27 \mu M$, which lies

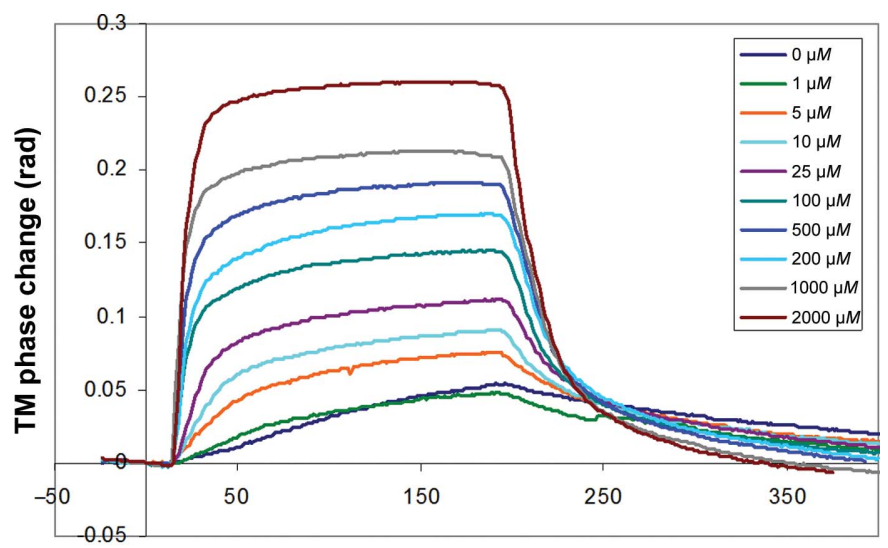

Time (s)

Figure 8

Experimental results of DPI measurements with HSA immobilized on the sensor chip. Raw phase change data in one polarization (transverse magnetic; TM) for a concentration series of $\mathrm{Cu}^{2+}$ injections of increasing concentrations.

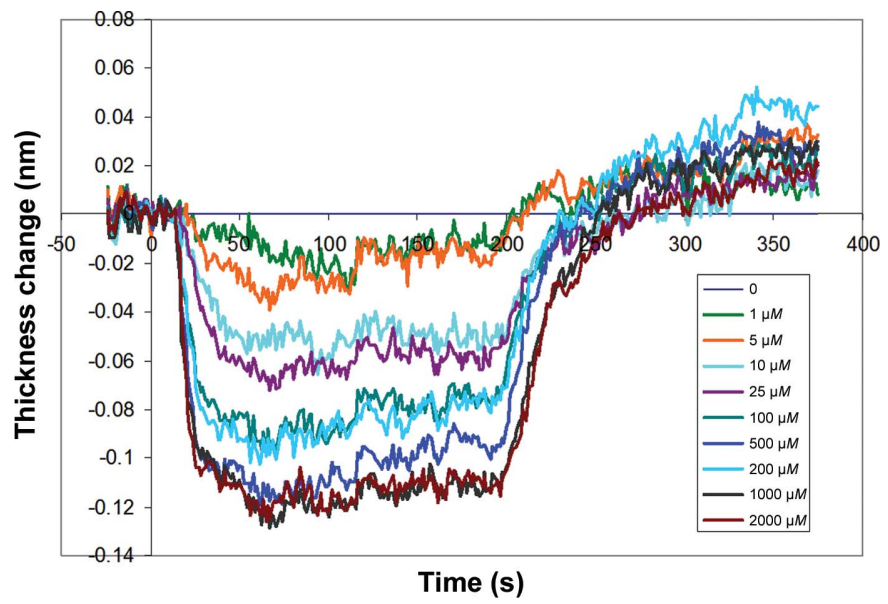

Figure 9

Real-time layer thickness for HSA incubated with $\mathrm{Cu}^{2+}$ ions at increasing concentrations. 
within the literature range of $0.23-110 \mu M$ (Sokołowska et al., 2010); however, a double-site affinity curve produces a better fit, with affinity constants of 15 and $99 \mu M$ (Fig. 11).

\section{Conclusions}

The two methods presented here represent two ends of the wide spectrum of biophysical methods for the characterization of biomolecular interactions. Thermal shift assays can be easily established and performed using standard equipment that is present in almost every molecular-biology or macromolecular laboratory. Examining dose-response relationships, TSA rarely provide a dissociation constant at physiological temperatures but allow the experimenter to distinguish between effects owing to specific binding (such as $\mathrm{Co}^{2+}$ binding to glucose isomerase) and nonspecific effects (for example the denaturing of glucose isomerase by increasing concentrations of guanidinium hydrochloride). They do, however, provide a good initial estimate of binding constants, which can facilitate the experimental setup for orthogonal approaches and is one of the few methods that is sensitive enough to examine binding affinities in the millimolar range.

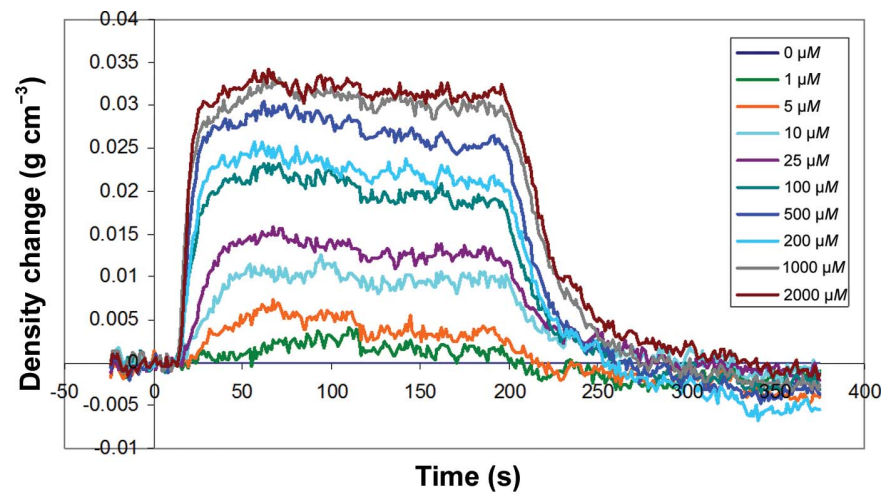

Figure 10

Layer-density change in response to a series of $\mathrm{Cu}^{2+}$ injections, showing the concentration-dependent densification of HSA upon $\mathrm{Cu}^{2+}$ binding.

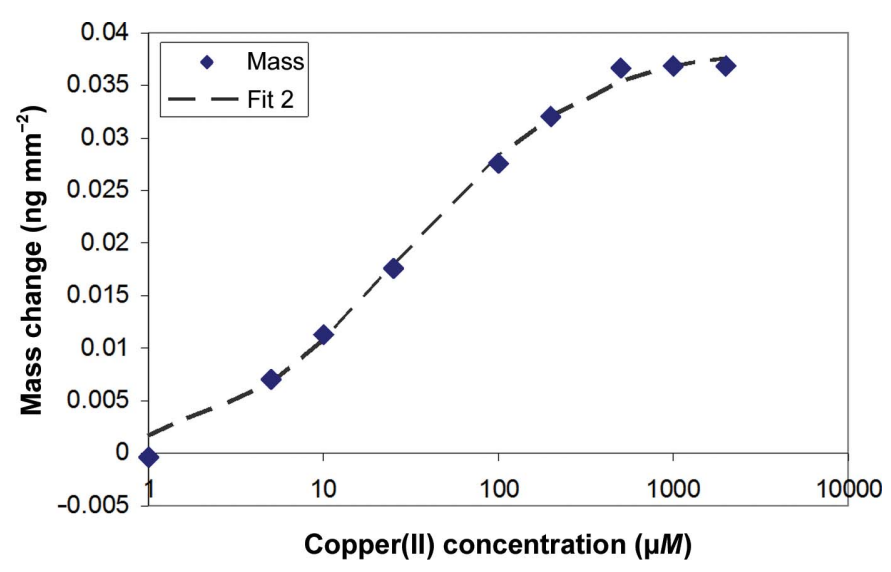

Figure 11

Mass change versus copper ion concentration from the experiments shown in Figs. 8 and 9. The dashed line corresponds to an affinity fit of two binding sites with copper affinities of 15 and $99 \mu M$.
TSA have been widely used to aid crystallization experiments and a number of screens have been described (Nettleship et al., 2008; Reinhard et al., 2013). The $\mathrm{pH}$ and salt screens presented here are currently being further optimized, as some of the initial conditions showed precipitation when stored at $4{ }^{\circ} \mathrm{C}$. One logical extension of the salt screen is the incorporation of heavy-atom compounds such as lanthanides to aid in phasing. TSA experiments are straightforward to adapt to a given set of conditions for a particular protein or problem, and they can easily be used to investigate specific protein-ligand interactions. Data can easily be analysed using a range of standard commercial software. Our program NAMI, which provides a user-friendly graphical interface coupled with automatic analysis and a wide range of graphical representations, is freely available from Github (http://github.com/grofte/ NAMI) under the three-clause BSD open-source licence.

Dual polarization interferometry, which shares many similarities with surface plasmon resonance, offers the advantage that binding events of one partner immobilized on a chip surface can be directly related in real time to alterations in layer thickness and refractive index, as well as mass. This means that in principle there is no a priori requirement for a net mass change to elucidate a binding or structural/conformational response: an aspect that has been utilized for studying $\mathrm{pH}$-induced changes in biopolymer (Westwood et al., 2013) and protein (Sheu et al., 2010) structures. Hence, DPI not only represents an alternative method to determine binding constants, but can also be used to provide information on molecular orientation and structural changes occurring during binding events. DPI can thus be used to identify and classify ligands with different modes of action leading to different structural changes upon binding.

We would like to thank Drs Graham Cross and Paul Denny for their ongoing support and many stimulating discussions, and Ian Edwards and Drs Mark Gostwock and Ian Cummins for their excellent support during the TSA and DPI experiments. Financial support from the Wellcome Trust (WT094759AIA) is gratefully acknowledged.

\section{References}

Bal, W., Sokołowska, M., Kurowska, E. \& Faller, P. (2013). Biochim. Biophys. Acta, 1830, 5444-5455.

Boudjemline, A., Saridakis, E., Swann, M. J., Govada, L., Mavridis, I. M. \& Chayen, N. E. (2011). Anal. Chem. 83, 7881-7887.

Carrell, H. L., Glusker, J. P., Burger, V., Manfre, F., Tritsch, D. \& Biellmann, J. F. (1989). Proc. Natl Acad. Sci. USA, 86, 4440-4444.

Coan, K. E., Swann, M. J. \& Ottl, J. (2012). Anal. Chem. 84, 15861591.

Cross, G. H., Reeves, A. A., Brand, S., Popplewell, J. F., Peel, L. L., Swann, M. J. \& Freeman, N. J. (2003). Biosens. Bioelectron. 19, 383-390.

Curry, S. (2009). Drug Metab. Pharmacokinet. 24, 342-357.

Ericsson, U. B., Hallberg, B. M., DeTitta, G. T., Dekker, N. \& Nordlund, P. (2006). Anal. Biochem. 357, 289-298.

Freyer, M. W. \& Lewis, E. A. (2008). Methods Cell Biol. 84, 79-113. Geders, T. W., Gustafson, K. \& Finzel, B. C. (2012). Acta Cryst. F68, 596-600.

Hirst, D. J., Lee, T.-H., Swann, M. J., Unabia, S., Park, Y., Hahm, K.-S. \& Aguilar, M. I. (2011). Eur. Biophys. J. 40, 503-514. 
Hofstadler, S. A. \& Sannes-Lowery, K. A. (2006). Nature Rev. Drug Discov. 5, 585-595.

Homola, J. (2008). Chem. Rev. 108, 462-493.

Jelesarov, I. \& Bosshard, H. R. (1999). J. Mol. Recognit. 12, 3-18.

Jerabek-Willemsen, M., Wienken, C. J., Braun, D., Baaske, P. \& Duhr, S. (2011). Assay Drug Dev. Technol. 9, 342-353.

Karim, K., Taylor, J. D., Cullen, D. C., Swann, M. J. \& Freeman, N. J. (2007). Anal. Chem. 79, 3023-3031.

Krintel, C., Frydenvang, K., Ceravalls de Rabassa, A., Kaern, A. M., Gajhede, M., Pickering, D. S. \& Kastrup, J. S. (2014). FEBS J. 281, 2422-2430.

Leavitt, S. \& Freire, E. (2001). Curr. Opin. Struct. Biol. 11, 560-566.

Lo, M.-C., Aulabaugh, A., Jin, G., Cowling, R., Bard, J., Malamas, M. \& Ellestad, G. (2004). Anal. Biochem. 332, 153-159.

Nettleship, J. E., Brown, J., Groves, M. R. \& Geerlof, A. (2008). Methods Mol. Biol. 426, 299-318.

Newman, J. (2004). Acta Cryst. D60, 610-612.

Oliphant, T. E. (2007). Comput. Sci. Eng. 9, 10-20.

Pantoliano, M. W., Petrella, E. C., Kwasnoski, J. D., Lobanov, V. S., Myslik, J., Graf, E., Carver, T., Asel, E., Springer, B. A., Lane, P. \& Salemme, F. R. (2001). J. Biomol. Screen. 6, 429-440.

Patching, S. G. (2014). Biochim. Biophys. Acta, 1838, 43-55.

Reinhard, L., Mayerhofer, H., Geerlof, A., Mueller-Dieckmann, J. \& Weiss, M. S. (2013). Acta Cryst. F69, 209-214.

Rich, R. L. \& Myszka, D. G. (2000). Curr. Opin. Biotechnol. 11, 54-61. Rodgers, T. L., Townsend, P. D., Burnell, D., Jones, M. L., Richards, S. A., McLeish, T. C., Pohl, E., Wilson, M. R. \& Cann, M. J. (2013). PLoS Biol. 11, e1001651.
Seidel, S. A. et al. (2013). Methods, 59, 301-315.

Semisotnov, G. V., Rodionova, N. A., Razgulyaev, O. I., Uversky, V. N., Gripas', A. F. \& Gilmanshin, R. I. (1991). Biopolymers, 31, 119-128.

Senisterra, G. A., Markin, E., Yamazaki, K., Hui, R., Vedadi, M. \& Awrey, D. E. (2006). J. Biomol. Screen. 11, 940-948.

Sheu, B.-C., Lin, Y.-H., Lin, C.-C., Lee, A. S.-Y., Chang, W.-C., Wu, J.-H., Tsai, J.-C. \& Lin, S. (2010). Biosens. Bioelectron. 26, 822-827.

Sillerud, L. O. \& Larson, R. S. (2012). Methods Mol. Biol. 910, 195-266.

Sokołowska, M., Pawlas, K. \& Bal, W. (2010). Bioinorg. Chem. Appl. 2010, 725153.

Swann, M. J., Peel, L. L., Carrington, S. \& Freeman, N. J. (2004). Anal. Biochem. 329, 190-198.

Tate, C. G. (2012). Trends Biochem. Sci. 37, 343-352.

Thibault, G., Yudin, J., Wong, P., Tsitrin, V., Sprangers, R., Zhao, R. \& Houry, W. A. (2006). Proc. Natl Acad. Sci. USA, 103, 17724-17729.

Tsvetkov, P. O., Barbier, P., Breuzard, G., Peyrot, V. \& Devred, F. (2013). Methods Cell Biol. 115, 283-302.

Tzeng, S. R. \& Kalodimos, C. G. (2009). Nature (London), 462, 368-372.

Vedadi, M. et al. (2006). Proc. Natl Acad. Sci. USA, 103, 15835-15840.

Westwood, M., Noel, T. R. \& Parker, R. (2013). Carbohydr. Polym. 94, 137-146.

Winter, A., Higueruelo, A. P., Marsh, M., Sigurdardottir, A., Pitt, W. R. \& Blundell, T. L. (2012). Q. Rev. Biophys. 45, 383-426.

Zwang, T. J., Patel, R., Johal, M. S. \& Selassie, C. R. (2012). Langmuir, 28, 9616-9620. 